UNIVERSITY OF WAIKATO

Hamilton

New Zealand

\title{
Cash versus Extra-Credit Incentives in Experimental Asset Markets
}

Shuze Ding, Volodymyr Lugovskyy, Daniela Puzzello, Steven Tucker and Arlington Williams

Working Paper in Economics 17/21

October 2017

\author{
Corresponding Author \\ Steven Tucker \\ Economics \\ University of Waikato \\ Private Bag 3105 \\ Hamilton, New Zealand, 3240 \\ Email: steven.tucker.nz@gmail.com
}

Shuze Ding

Economics Department, Indiana University

Bloomington, Illinois

USA, IN47405-7104

Email: dings@indiana.edu

Daniela Puzzello

Economics Department, Indiana University Email: dpuzzell@indiana.edu
Volodymyr Lugovskyy

Economics Department, Indiana University

Email: vlugovsk@indiana.edu

\section{Arlington Williams}

Economics Department, Indiana University

Email: williama@indiana.edu 


\begin{abstract}
The research community in experimental economics has been increasingly encouraged to replicate studies and increase the sample size. While these suggestions have strong advantages, they also potentially increase the financial costs associated with data collection and, as a result, tamper the growth of experimental economics and limit the questions that may be addressed using experimental methods. In this paper, we explore the effectiveness of extra-credit as a reward medium, since it is financially less taxing. We focus on experimental asset markets since data is more costly to collect for these experiments, for example, a market (consisting of 8 to 12 traders) is an observation. Our treatment variable is the reward medium, either extra-credit or cash. We compare bubble measures in the two treatments and we find that bubbles observed in the extra-credit sessions are not significantly different from bubbles observed in the cash sessions. These results suggest that extra-credit is an effective reward medium in experimental asset markets.
\end{abstract}

\title{
JEL Classification
}

C91

\section{Keywords}

asset market experiments

experiment incentives 


\title{
CAsh versus Extra-CREdit InCentives in Experimental Asset
}

\section{MARKETS}

\author{
Shuze Ding* Volodymyr Lugovskyy ${ }^{\dagger}$ Daniela Puzzello ${ }^{\ddagger}$ Steven Tucker ${ }^{\S}$ \\ Arlington Williams
}

October 5, 2017

\begin{abstract}
The research community in experimental economics has been increasingly encouraged to replicate studies and increase the sample size. While these suggestions have strong advantages, they also potentially increase the financial costs associated with data collection and, as a result, tamper the growth of experimental economics and limit the questions that may be addressed using experimental methods. In this paper, we explore the effectiveness of extra-credit as a reward medium, since it is financially less taxing. We focus on experimental asset markets since data is more costly to collect for these experiments, e.g., a market (consisting of 8-12 traders) is an observation. Our treatment variable is the reward medium, either extra-credit or cash. We compare bubble measures in the two treatments and we find that bubbles observed in the extracredit sessions are not significantly different from bubbles observed in the cash sessions. These results suggest that extra-credit is an effective reward medium in experimental asset markets.
\end{abstract}

${ }^{*}$ Department of Economics, Indiana University, Wylie Hall, 100 S. Woodlawn, Bloomington, IN 474057104; e-mail: dings@indiana.edu

†Department of Economics, Indiana University, Wylie Hall Rm 301, 100 S. Woodlawn, Bloomington, IN 47405-7104; e-mail: vlugovsk@indiana.edu

${ }^{\ddagger}$ Department of Economics, Indiana University, Wylie Hall Rm 314, 100 S. Woodlawn, Bloomington, IN 47405-7104; e-mail: dpuzzell@indiana.edu

$\S$ Department of Economics, University of Waikato, email: steven.tucker.nz@gmail.com

"Department of Economics, Indiana University, Wylie Hall, 100 S. Woodlawn, Bloomington, IN 474057104; e-mail: williama@indiana.edu 


\section{Introduction}

Experiments in economics are run for several purposes: test a theory, guide the design of market mechanisms and institutions, inform the implementation of economic policies.

In order to foster scientific progress or avoid misallocation of resources, it is desirable that conclusions drawn from experimental economics studies are accurate and robust. Indeed, the research community in experimental economics has been increasingly encouraged to replicate studies or collect larger samples (Camerer et al. (2016), Butera and List (2017) and List et al. (2016)).

While these suggestions have strong advantages, it is our view that they have the potential to threaten the unbiased growth of the experimental economics field. In particular, given that access to external funding is extremely competitive and that financial costs associated with significant increases in sample sizes are substantive, there is a risk of turning experimental economics in an elitarian field. Furthermore, due to cost constraints, they may limit the questions that may be addressed using experimental methods, e.g., asset markets experiments are very expensive as they require 8-10 people for a single observation. Experimental macroeconomics, where markets may consist of 14 or more traders, may be plagued even more by these constraints.

These concerns may be alleviated by the exploration of alternative incentive mechanisms whose financial costs are more reasonable. An example of such incentive mechanism is given by course extra credit.1

Clearly performance-based incentives are an important cornerstone of experimental economics (e.g., Smith (1976)), and while cash is the dominant reward $2^{2}$ it is an empirical question whether other reward media work well and under what conditions.

Extra-credit has been used as a reward medium in several studies (Kormendi and Plott (1982), Isaac et al. (1994), Pouget (2007), Biais et al. (2005), Selten et al. (1997)). There are other studies that have used extra-credit as a reward medium and compared their results to other experiments which used cash (e.g., Dickinson (2009), Kormendi and Plott (1982), Isaac et al. (1994)). While these studies indicate that extra-credit is a salient reward medium, with the exception of Dickinson (2009) (who compares his results to some of the results obtained by Andreoni and Miller (2002)), they are not designed to test directly the hypothesis that extra-credit is as salient of a reward as cash, since the reward medium is not an explicit treatment variable and thus confounding effects may be present.

Our paper is closest to studies which have employed the reward medium (cash vs. extracredit) as treatment variable (Luccasen and Thomas (2014), Grossman and Komai (2006), Kruse and Thompson (2001)). These studies focus on game theoretic settings or individual

\footnotetext{
${ }^{1}$ While cash incentives are the dominant incentive medium in laboratory experiments, other reward media are used in field studies. Also, in experimental studies involving children, toys are used as an effective incentive mechanism.

${ }^{2}$ See Camerer et al. (1999) for a review of studies employing low, medium and high financial incentives.
} 
decision making situations. In this paper we compare results from an asset market experiment where the treatment variable is the reward medium, namely either cash or extra-credit class points. We chose to focus on asset markets since they appeal to economists as well as policy makers, and the advantages of using extra-credit may be sizable for these environments since they involve the participation of a high number of subjects. Indeed, the need to study large markets or collect a high number of observations may easily drive up the cost of conducting market experiments.

We find that bubbles are not significantly different across the cash and extra-credit treatments. This result suggest that extra-credit can be used to substitute or complement cash as a reward medium. In particular, extra-credit may be used to contain research costs in the face of budget constraints. Our result also reinforces the idea that experiments can be effectively used for educational purposes if performance-based extra-credit is used to incentivize participation.

\section{Literature Review}

There are several studies that explore the saliency of performance-based monetary rewards or make use of extra-credit as a reward medium either in isolation or in combination with cash (e.g., Dickinson (2009), Isaac et al. (1994), Jamal and Sunder (1991), Kormendi and Plott (1982), Pouget (2007), Biais et al. (2005), Selten et al. (1997), Smith and Walker (1993), Camerer et al. (1999)).

However, to the best of our knowledge only few studies provide a direct comparison by using the reward medium- cash or extra-credit- as a treatment variable (Luccasen and Thomas (2014), Grossman and Komai (2006), Kruse and Thompson (2001)).

Our paper contributes to this literature by providing a direct comparison of cash versus extra-credit as a reward medium in experimental asset markets. We chose to focus on market environments since they appeal to economists as well as policy makers, and the advantages of using extra-credit may be sizable for these environments. Specifically, the need to study large markets or collect a high number of observations may easily drive up the cost of conducting market experiments. As described below, other studies comparing extra-credit and cash as a reward medium have mainly focused on individual decision making problems or game theoretic settings.

We start by providing a quick review of studies that have employed extra-credit as a reward medium. Selten et al. (1997) study strategies in 20-period supergames of an asymmetric Cournot duopoly. In order to gain experience, subjects participate in three 20-period supergames which were one week apart. Selten et al. (1997) use class-points to incentivize subjects as they find it a more convenient reward medium, given that the same cohort of subjects was required to participate in the experiment over time. Selten et al. (1997) write "In view of the length of the experiment, it was not possible to provide an appropriate financial 
incentive. Presumably, money payoffs in the framework of a student seminar are not legal anyhow. The students were told that their grades would strongly depend on their success in the last tournament. It was emphasized that the absolute payoff sum rather than the rank was important in this respect. We had the impression that for almost all participants the task itself provided a high intrinsic motivation." Pouget (2007) uses class points to incentivize subjects in an experiment designed to compare the Call Market and Walrasian Tatonnement trading institutions in an environment with asymmetric information. Biais et al. (2005) also use class points in an experiment studying how overconfidence and self-monitoring affect trading performance of traders.

Other studies employ extra-credit to incentivize subjects and compare the results obtained for extra-credit with results obtained with cash as a reward medium. Dickinson (2009) conducts dictator games designed to elicit preferences for fairness (as in Andreoni and Miller (2002)). Dickinson (2009) uses extra-credit points as a reward medium and he compares his results with the results found in Andreoni and Miller (2002), who incentivized subjects using cash. He finds that classroom points are a salient reward medium relative to cash.

Williams (2008) studies behaviour in asynchronous experimental asset markets where subjects receive extra-credit points instead of cash rewards. He finds that bubbles' patterns in experiments using extra-credit as a reward medium are similar to the ones observed in synchronous experimental asset markets where cash is the reward medium. However, while this finding provides support for the use of extra-credit as a substitute for cash, it is worth pointing out that the reward medium is not the only difference between these experiments as the extra-credit sessions consist of asynchronous asset market $?^{3}$

Kormendi and Plott (1982) study committee decisions under different rules (simple majority rule versus closed rule) and use class credit as the reward medium. The experimental results show that deviations of observed outcomes from predicted outcomes are similar to previous experiments by Fiorina and Plott (1978) for the treatment providing high financial incentives $4^{4}$ even though class credit earnings were computed differently than the cash earnings $5^{5}$ Regarding extra-credit as a reward medium, Kormendi and Plott (1982) write

$\sqrt[3]{\text { Williams }}(2008)$ writes "Trading occurred over fifteen rounds lasting a total of approximately eight weeks. Round 1, which includes completing the computer-based instructions, was typically 7-10 days long, but rounds 2 through 15 were all 3.5 days long. Students could access the market software at a time of their own choosing and as often as they wanted during each trading round in order to view the market bid and ask arrays, the tentative market price and volume, and edit their personal bid or ask. ... Performancebased extra-credit points were awarded using a rank-order tournament focusing on the traders? final cash holdings." As indicated by the last sentence, not only the reward medium was extra-credit but it was also awarded based on a rank-order tournament, which is a different mechanism than the one typically employed when cash is used as a reward medium.

${ }_{4}^{4}$ Fiorina and Plott (1978) observe high deviations of the observed outcome from the predicted outcome when low financial incentives are used.

5 Kormendi and Plott (1982) write "Points awarded to students towards their grades were determined by their ordinal rankings relative to other 'similarly situated' students, i.e., those with the same member 
"relative to the core model of group choices, our method seems to have motivated performance at least as well as significant financial incentives did."

Isaac et al. (1994) focus on the difference between contributions in small groups and large groups in linear voluntary contribution mechanism public goods games (VCM). They focus on groups of size 4, 10, 40 and 100. The larger group size is not the only difference between VCM laboratory studies and their study. Specifically, in addition to the larger group sizes, contributions decision rounds last several days rather than few minutes and extra-credit is used as a reward medium rather than cash (these departures made easier the implementation of large groups VCM games especially for groups of 100 subjects). The comparison between laboratory cash single-session and extra-credit multiple-session for groups of 4 and 10 reveal a very similar pattern of contributions. However, contributions for groups of 40 are lower in multiple-session extra credit experiments than cash single-session experiments. Since the reward medium is not the only difference between the two treatments it is not clear where the difference stems from. Baker et al. (2009) study how different institutions, lump-sum matching and one-to-one matching, affect contributions in public goods games using cash rewards. Baker et al. (2011) show that the results in Baker et al. (2009) are robust to allowing students to make decisions across rounds that lasted several days and to a mixed reward scheme involving extra-credit and cash.

Overall, these studies suggest that extra-credit is a salient reward medium, thus calling for a more controlled comparison of extra-credit and cash as reward media. Indeed, our study is more closely related to studies that provide a direct comparison of cash and extracredit as a reward medium (Luccasen and Thomas (2014), Grossman and Komai (2006), Kruse and Thompson (2001)). These studies employ an across subjects design where the treatment variable is the reward medium, namely cash versus extra-credit. Luccasen and Thomas (2014) find similar average rates of trust and trustworthiness in a trust game when extra-credit or cash are used as a reward medium. They conclude that extra-credit can be used as a substitute for cash (for reasonable monetary incentives) in trust games.

Grossman and Komai (2006) find that subjects' behaviour in some cases is closer to the theoretical predictions of a three-person investment game when extra credit points are used to incentivize subjects $5^{6}$ Kruse and Thompson (2001) study the maximum price that subjects are willing to pay for a protective opportunity that decreased the probability of a loss from $2 \%$ to $1 \%$. They find gender differences when extra-credit is used as reward

number in other committees with the same experimental instructions. Students in the top 20 percent were given two points towards their final grade, students in the second 20 percent were given one point. No points were given to students in the lower 60 percent. These point awards were in addition to a total of one hundred class points available on the exams." A rank-order tournament mechanism was not used in Fiorina and Plott (1978) when cash was used as a reward medium.

'Grossman and Komai (2006) conducted two treatments. Subjects' behavior in the complete information treatment of the investment game was not significantly different between the extra-credit and cash experiments. Subjects' behavior in the incomplete information treatment of the investment game is closer to the theoretical predictions when extra-credit points are used as a reward medium. 
medium. In particular, females are relatively more risk loving when extra-credit points are used as a reward medium.

\section{Hypothesis and Experimental Procedures}

As reported in Section 2, existing experimental evidence suggests that extra credit is an effective reward medium in individual choice and game theoretic settings. Motivated by these findings, we formulate our hypothesis.

Hypothesis 1. Bubbles observed in the Cash sessions are not significantly different from bubbles observed in the Extra Credit sessions.

The experimental design was based upon the Smith et al. (1988) paradigm. In each market, seven to twelve subjects traded an asset over a sequence of 15 periods (see Table 1 for more details). At the end of each period, each unit of the asset paid an uncertain dividend that was drawn from a four-point distribution of $0,8,28$ or 60 francs (experimental currency) with equal probability, which was the same for all traders. Therefore, the expected value of the dividend payment in any period was equal to 24 francs. Dividend payments were the only source of income from the assets. Given the commonly known finite trading horizon of 15 periods, the fundamental value of the asset could easily be calculated at any point during the market. More specifically, the fundamental value of the asset in period t equalled the expected future dividend stream, i.e. $24^{*}(16-\mathrm{t})$, and thus the fundamental value of the asset was declining from 360 francs in period 1 to 24 francs in period 15. This information was illustrated in the Average Holding Value Table in the instructions as well as summarized on the subjects' bidding screen $7^{7}$ Even though the dividend process was described in detail, there was no suggestion of a relationship between the fundamental value and transaction price. At the beginning of the experiment, each subject was endowed with 10,000 francs and 10 units of the asset. Therefore, the cash-to-asset ratio (see Caginalp et al., 2001) at the beginning of the market was equal to 2.77 .8

The trading institution used in all markets was the closed-book call market. Traders simultaneously submitted buy and/or sell limit orders.9 The computer generated demand and supply schedules by ordering the buy orders from highest to lowest and sell orders from lowest to highest. The market clearing price, at which all trades took place, was determined by the intersection of the demand and supply schedules. If the schedules overlapped, the

\footnotetext{
${ }^{7}$ The following information was also presented on the bidding screen: current period, time remaining within the current period, periods remaining in the market, average dividend per period, maximum and minimum values of outstanding dividend stream, cash holdings and asset holdings.

${ }^{8}$ The dividend payments at the end of each period were added to the traders' working capital. Therefore, the cash-to-asset ratio grew in expectation each period to a final value of 56.66 in period 15 .

${ }^{9}$ If subjects wanted to submit both buy and sell limit orders, the price to buy must be less than the price to sell in order to avoid self-trades.
} 
Table 1: Characteristics of Sessions

\begin{tabular}{llc}
\hline Session No. & Treatment & Number of Subjects \\
\hline 1 & Extra Credit & 9 \\
2 & Extra Credit & 10 \\
3 & Extra Credit & 11 \\
4 & Extra Credit & 9 \\
5 & Extra Credit & 9 \\
6 & Extra Credit & 9 \\
7 & Extra Credit & 10 \\
8 & Extra Credit & 7 \\
9 & Extra Credit & 9 \\
10 & Extra Credit & 12 \\
11 & Extra Credit & 9 \\
12 & Extra Credit & 8 \\
13 & Cash & 9 \\
14 & Cash & 9 \\
15 & Cash & 9 \\
16 & Cash & 9 \\
17 & Cash & 8 \\
18 & Cash & 9 \\
\hline
\end{tabular}

highest sell offer resulting in a profitable trade determined the market clearing price. If the entire supply schedule was greater than the entire demand schedule, then the highest buy order was reported as the market clearing price with no trade occurring. Short selling and borrowing cash for purchases was not allowed. No transaction costs were imposed and no interest was paid on cash holdings.

The only treatment variable in this study is the incentive structure, i.e. monetary payments vs. course extra credit payments. In both treatments, the conversion rate from francs to cash (740 francs to 1 US dollar) and extra credit (10,000 francs to 1 extra credit point) were predetermined and publicly known. The extra credit points were added to the course final weighted average, i.e. each extra credit point equalled 1 percentage point in final grade. The following text was provided in the instructions:

Your participation in this exercise is totally voluntary. It is possible to get an $A+$ in this class based solely on your examination and homework scores. Extra-credit points can only improve upon the course grade you earn based on your exam and homework scores. At the end of the semester, extra-credit points are added to the weighted average of your scores to determine your semester grade in this course. For example, if the weighted average of your scores is 88, three extra-credit points will raise your semester grade to a 91 .

At the beginning of each period, subjects were asked to forecast the market clearing price 
for that period. They received rewards in terms of francs for the accuracy of their forecasts 10 All earnings from forecasts accumulated in a separate account from their working capital, and thus the market cash-to-asset ratio was unaffected by these rewards.

The timing of events in each session was as follows. ${ }^{11}$ (1) Subjects entered the computer lab and chose a computer terminal for use during the session. (2) Instructions for the asset market were distributed. The subjects were provided 15 minutes to read them on their own. Afterwards, the experimenter read a bullet point summary and provided a discussion of the trading interphase. (3) Subjects completed a short quiz on the dividend process, after which the experimenter checked the answers and privately answered any questions they may have. (4) The z-Tree asset market program was started. (5) Upon completion of the market, subject earnings were calculated. In the monetary treatment, subjects privately received their cash payments. In the extra credit treatment, subjects were privately notified of the extra credit points received. This information was passed on to their professor for inclusion into the final grade.

The experiment consisted of 18 sessions conducted at Indiana University in October, 2012. A total of 165 subjects participated in the study. Subjects for both treatments were recruited from a range of undergraduate economics courses. Some subjects may have participated in pervious economics experiments, but none had experience with asset markets. All subjects participated in only a single session of this study. The experiments were computerized and programmed with the z-Tree software package (Fischbacher, 2007). Each session lasted approximately one hour, and the average earnings from trading were on average 18.4 US dollars and 1.4 course extra credit points in their respective treatments.

\section{Experimental Results}

Figure 1 depicts the time series of prices and fundamental values in our experiment for each session of Cash and Extra Credit treatments, respectively. The horizontal axis depicts periods, while the vertical axis depicts market clearing prices. Figure 2 shows the average prices and the fundamental value across all sessions under the two treatments.

To analyze potential differences in bubbles' formation between treatments, we calculated several bubble measures typically used in the literature. We focus on several measures as they provide a more complete picture of bubbles, as each measure captures a different aspect. The definitions of measures and their median values are showed in Table 1.

Specifically, Turnover is given by the total sum of the number of shares traded in each

\footnotetext{
${ }^{10}$ Following the forecast procedures of Haruvy et al. (2007), subjects received 50 francs for forecasts within $10 \%$ of the actual price, 20 francs if within $25 \%$ of the actual price, 10 francs if within $50 \%$ of the actual price, and 0 francs otherwise.

${ }^{11}$ A cognitive reflection test (Frederick, 2005) was conducted at the beginning of each session to be used for a different study, and thus those results are not reported in this paper.
} 


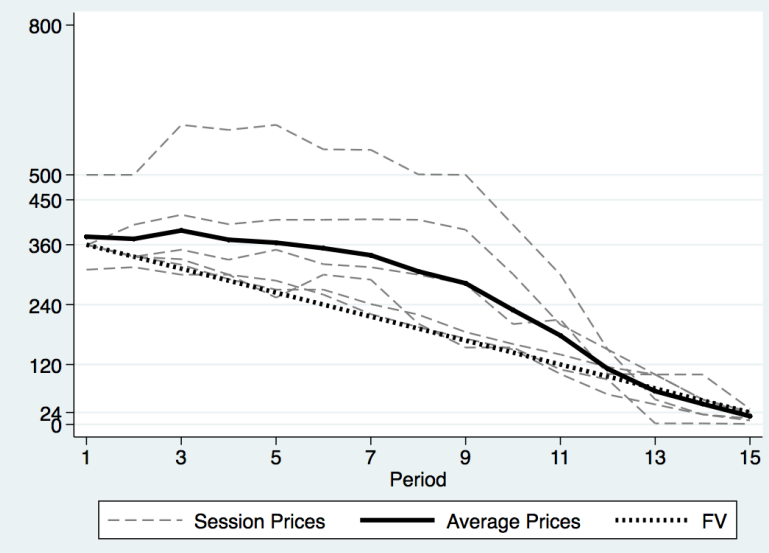

(a) Cash Sessions

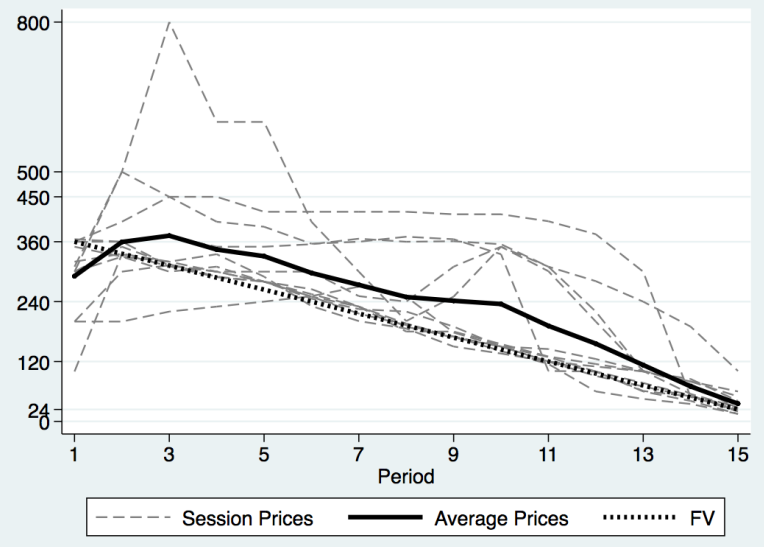

(b) Extra Credit Sessions

Figure 1: Time series of transaction prices, all sessions.

Notes. Dashed gray lines: session prices. Solid lines: average prices. Dashed black line: fundamental value of the asset.

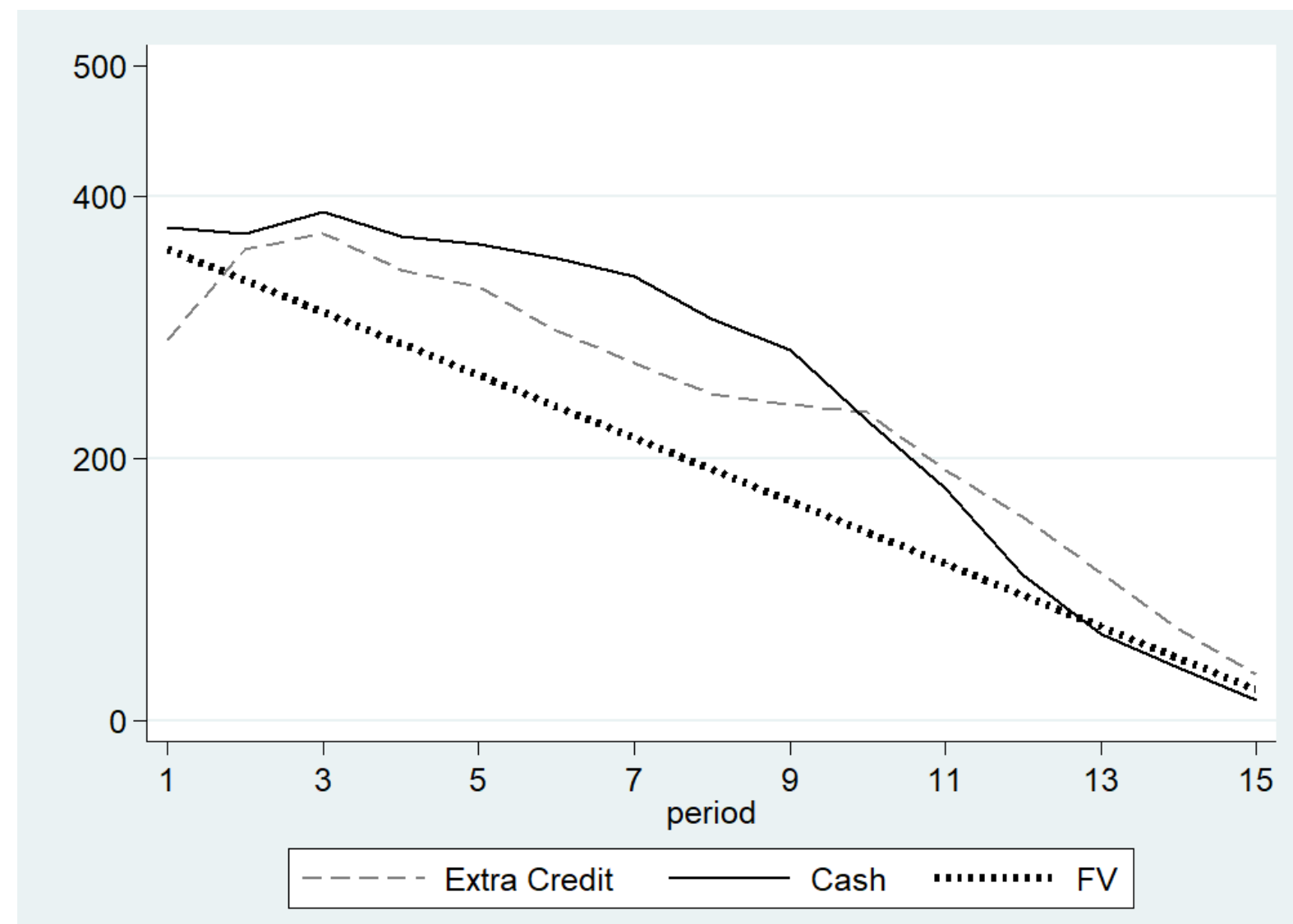

Figure 2: Treatment average prices.

Notes. Dashed black line: fundamental value of the asset. 
period $\left(q_{t}\right)$ normalized by the total number of shares (TSU). A high turnover indicates high volume of trade, which can be an indication of a bubble.

Amplitude is defined as the difference between the maximum of the deviation of the price from fundamental value across all time periods and the minimum of the deviation of the price from fundamental value across all time periods, normalized by the fundamental value at period 1. A high amplitude value indicates the presence of large price swings.

Absolute Price Deviation (APD) is defined as the sum, over all 15 periods, of the absolute deviation of period price, $P_{t}$, from period fundamental value, $F V_{t}$, normalized by the total number of shares. A high APD indicates that prices depart from fundamental value.

Normalized Absolute Price Deviation (NAPD) is given by the sum, over all 15 periods, of the absolute deviation of period price from fundamental value normalized by the total number of shares, total number of time periods and the fundamental value at time period 1 .

In the Normalized Deviation (Norm. Dev.), these period differences are weighted by the number of units traded. A high Normalized Deviation indicates a considerable volume of trade at prices that depart from the fundamental value.

In the Relative Absolute Deviation (RAD), on the other hand, these period differences are normalized by the average fundamental value, and in the Relative Proportional Absolute Deviation (RPAD) period differences are normalized by the period fundamental values.

The Relative Deviation (RD) differs from the RAD in that it takes the difference between period price and period fundamental value rather than the absolute difference. Thus a high RAD indicates departures of prices from fundamentals, while RD indicates also the direction, that is, a positive RD indicates that prices tend to be above fundamental value while a negative RD may indicate the presence of negative bubbles.

Haessel is a measure of correlation of prices with fundamental value, thus a low Haessel indicates that transactions prices do not follow the fundamental value.

Table 2 indicates that most of the bubble measures are only slightly different under different treatments. Importantly, none of these differences is statistically significant.

Result 1. Bubble measures in the ExtraCredit treatment are not significantly different from bubble measures in the Cash treatment.

We compared bubble measures across treatments using a two-sided Mann-Whitney test as well as a t-test (with each session as the unit of observation). The results are presented in the last two columns of Table 2, which reports the p-values associated with the test. Both tests do not reject the null hypotheses that bubble measures are not different across treatments. Specifically, all p-values are above 0.1, and, with the exception of Turnover and Haessel, p-values for all other measures are at least 0.45 .

This result suggests that extra-credit is an effective reward medium in experimental asset markets. 
Table 2: Medians of Bubble Measures for All Sessions, by Treatment

\begin{tabular}{|c|c|c|c|c|}
\hline Measures & Extra Credit & Cash & $\begin{array}{c}\mathrm{p} \text {-value } \\
\text { Mann-Whitney test } \\
\text { Extra Credit vs. }\end{array}$ & $\begin{array}{l}\mathrm{p} \text {-value } \\
\text { t test } \\
\text { Cash }\end{array}$ \\
\hline Turnover $=\sum_{t=1}^{15} q_{t} / T S U$ & 1.22 & 1.05 & 0.22 & 0.21 \\
\hline Amplitude $=\max _{t}\left\{\frac{P_{t}-F V_{t}}{F V_{1}}\right\}-\min _{t}\left\{\frac{P_{t}-F V_{t}}{F V_{1}}\right\}$ & 0.60 & 0.36 & 0.64 & 0.45 \\
\hline $\mathrm{APD}=\frac{1}{T S U} \sum_{t=1}^{15}\left|P_{t}-F V_{t}\right|$ & 6.30 & 7.15 & 0.64 & 0.80 \\
\hline $\mathrm{NAPD}=\frac{1}{15 * T S U * F V_{1}} \sum_{t=1}^{15}\left|P_{t}-F V_{t}\right|$ & 0.01 & 0.01 & 0.64 & 0.88 \\
\hline Norm. Dev. $=\frac{1}{T S U} \sum_{t=1}^{15} q_{t}\left|P_{t}-F V_{t}\right|$ & 50.04 & 46.76 & 0.64 & 0.88 \\
\hline $\mathrm{RAD}=\frac{1}{15} \sum_{t=1}^{15} \frac{\left|P_{t}-F \bar{V}_{t}\right|}{\operatorname{mean}(F V)}$ & 0.17 & 0.21 & 0.78 & 0.83 \\
\hline $\mathrm{RD}=\frac{1}{15} \sum_{t=1}^{15} \frac{\left(P_{t}-F \grave{V}_{t}\right)}{\operatorname{mean}(F V)}$ & 0.07 & 0.17 & 0.78 & 0.72 \\
\hline $\mathrm{RPAD}=\frac{1}{15} \sum_{t=1}^{15} \frac{\left(P_{t}-F V_{t}\right)}{F V_{t}}$ & 0.21 & 0.32 & 0.85 & 0.99 \\
\hline Haessel $=R^{2}$ of OLS regression $P_{t}=\alpha+\beta F V_{t}+\epsilon_{t}$ & 0.70 & 0.89 & 0.22 & 0.12 \\
\hline
\end{tabular}

\section{Conclusions}

Experimental economists are increasingly encouraged to replicate and increase their sample sizes in order to make more accurate and robust inferences from their studies. While these suggestions are well-taken, they also have the potential to tamper the unbiased growth of experimental economics or limit the questions that may be addressed using experimental methods. One way to alleviate these concerns is to explore more economical reward media. In this paper we explored the effect of extra-credit on bubble formation and we found that bubbles in the extra-credit treatment are not significantly different from bubbles in the cash treatment. Therefore, our study suggests that extra-credit can be used to incentivize subjects in experimental asset markets.

\section{References}

Andreoni, J., Miller, J., 2002. Giving according to garp: An experimental test of the consistency of preferences for altruism. Econometrica 70 (2), 737-753.

Baker, R. J., Walker, J. M., Williams, A. W., 2009. Matching contributions and the voluntary provision of a pure public good: Experimental evidence. Journal of Economic Behavior \& Organization 70 (1), 122-134.

Baker, R. J., Walker, J. M., Williams, A. W., 2011. An exploration of the robustness of alternative laboratory methodologies: Matching funds and the provision of public goods. The Journal of Socio-Economics 40 (6), 763-774.

Biais, B., Hilton, D., Mazurier, K., Pouget, S., 2005. Judgemental overconfidence, selfmonitoring, and trading performance in an experimental financial market. The Review of economic studies 72 (2), 287-312. 
Butera, L., List, J. A., 2017. An economic approach to alleviate the crises of confidence in science: With an application to the public goods game. Tech. rep., National Bureau of Economic Research.

Camerer, C. F., Dreber, A., Forsell, E., Ho, T.-H., Huber, J., Johannesson, M., Kirchler, M., Almenberg, J., Altmejd, A., Chan, T., et al., 2016. Evaluating replicability of laboratory experiments in economics. Science 351 (6280), 1433-1436.

Camerer, C. F., Hogarth, R. M., Budescu, D. V., Eckel, C., 1999. The effects of financial incentives in experiments: A review and capital-labor-production framework. In: Elicitation of Preferences. Springer, pp. 7-48.

Dickinson, D. L., 2009. Experiment timing and preferences for fairness. The Journal of SocioEconomics 38 (1), 89-95.

Fiorina, M. P., Plott, C. R., 1978. Committee decisions under majority rule: An experimental study. American Political Science Review 72 (2), 575-598.

Grossman, P. J., Komai, M., 2006. 1 incentivizing experiments: Monetary rewards versus extra credits.

Isaac, R. M., Walker, J. M., Williams, A. W., 1994. Group size and the voluntary provision of public goods: Experimental evidence utilizing large groups. Journal of public Economics $54(1), 1-36$.

Jamal, K., Sunder, S., 1991. Money vs gaming: Effects of salient monetary payments in double oral auctions. Organizational Behavior and Human Decision Processes 49 (1), 151166.

Kormendi, R. C., Plott, C. R., 1982. Committee decisions under alternative procedural rules: An experimental study applying a new non-monetary method of preference inducement. Journal of Economic Behavior \& Organization 3 (2-3), 175-195.

Kruse, J. B., Thompson, M. A., 2001. A comparison of salient rewards in experiments: money and class points. Economics Letters 74 (1), 113-117.

List, J. A., Shaikh, A. M., Xu, Y., 2016. Multiple hypothesis testing in experimental economics. Tech. rep., National Bureau of Economic Research.

Luccasen, R. A., Thomas, M. K., 2014. Monetary incentives versus class credit: Evidence from a large classroom trust experiment. Economics Letters 123 (2), 232-235.

Pouget, S., 2007. Financial market design and bounded rationality: An experiment. Journal of Financial Markets 10 (3), 287-317. 
Selten, R., Mitzkewitz, M., Uhlich, G. R., 1997. Duopoly strategies programmed by experienced players. Econometrica: Journal of the Econometric Society, 517-555.

Smith, V. L., 1976. Experimental economics: Induced value theory. The American Economic Review 66 (2), 274-279.

Smith, V. L., Suchanek, G. L., Williams, A. W., 1988. Bubbles, crashes, and endogenous expectations in experimental spot asset markets. Econometrica: Journal of the Econometric Society, 1119-1151.

Smith, V. L., Walker, J. M., 1993. Monetary rewards and decision cost in experimental economics. Economic Inquiry 31 (2), 245-261.

Stöckl, T., Huber, J., Kirchler, M., 2010. Bubble measures in experimental asset markets. Experimental Economics 13 (3), 284-298.

Williams, A. W., 2008. Price bubbles in large financial asset markets. Handbook of Experimental Economics Results 1, 242-246. 